\title{
SOME MAXIMUM PRINCIPLES FOR A CLASS OF ELLIPTIC BOUNDARY VALUE PROBLEMS
}

\author{
C. EnAche And G. A. Philippin
}

Abstract. For a class of elliptic boundary value problems we construct, in this paper, some general elliptic inequalities from which we derive maximum principles and we also give some applications in physics and geometry of surfaces.

Mathematics subject classification (2000): 35J25, 35B50, 35B45.

Key words and phrases: elliptic equations, maximum principles, a priori bounds.

\section{REFERENCES}

[1] E. HopF, Elementare Bemerkung über die Lösung partieller Differentialgleichungen zweiter Ordnung vom elliptischen Typus, Berlin Sber. Preuss. Akad. Wiss, 19, (1927), 147-152.

[2] E. Hopf, A remark on linear elliptic differential equations of the second order, Proc. Amer. Math. Soc., 36, (1952), 791-793.

[3] KrYLov, Nonlinear Elliptic and Parabolic Equations of the Second Order, Kluwer Academic Publishers Group, (2001).

[4] O. A. Ladyzenskaja, N. N. Ural'Ceva, Équations aux dérivées partielles de type elliptique, Dunod, Paris, (1968).

[5] L. E. PAYNE, Bounds for the maximum stress in the Saint-Venant torsion problem, Ind. J. Mech. Math., (1968), 51-59.

[6] L. E. PAYNe, G. A. PhiLIPPIN, Some applications of the maximum principle in the problem of torsional creep, SIAM J. Appl. Math, 33, (1977), 446-455.

[7] L. E. PAYNe, G. A. PhILIPPIN, Some maximum principles for nonlinear elliptic equations in divergence form with applications to capillary surfaces and to surfaces of constant mean curvature, Nonlin. Anal, 3, (1979), 193-211.

[8] L. E. PAYNE, I. STAKGOLD, On the mean value of the fundamental mode in the fixed membrane problem, Appl. Analysis, 1, (1973), 295-303.

[9] G. A. PHILIPPIN, On the first eigenfunction of the fixed membrane: Some extensions of results of Payne and Stackgold, ZAMP, 28, (1977), 151-159.

[10] G. A. PHILIPPIN, Some remarks on the elastically supported membrane, ZAMP, 29, (1978), 306-314.

[11] M. H. Protter, H. F. WeinBerger, Maximum principles in differential equations, Springer Verlag, (1975).

[12] P. W. SCHAEFER, Some maximum principles for nonlinear elliptic boundary value problems, Q. appl. Math., 35, (1977), 517-523.

[13] P. W. SCHAEFER, R. P. SPERB, Maximum principles and bounds in some inhomogeneous elliptic boundary value problems, SIAM J. Math. Analysis, 8, (1977), 871-878.

[14] P. W. SCHAEFER, R. P. SPERB, Maximum principles for some functionals associated with the solution of elliptic boundary value problems, Arch. Rat. Mech. Anal., 61, (1976), 65-76.

[15] J. B. SERRIN, Gradient estimates for solutions of nonlinear elliptic and parabolic equations, Contributions to Nonlinear functional analysis, Univ. of Wisconsin, Academic Press, (1971), 565-601.

[16] J. B. SERRIN, The problem of Dirichlet for quasilinear elliptic differential equations with many independent variables, Phil. Trans. R. Soc. London, 264, (1969), 413-496

[17] R. P. SPERB, Maximum Principles and Their Applications, Academic Press, (1981). 